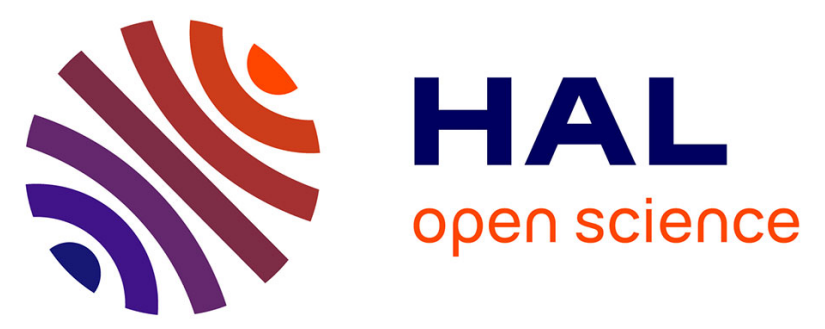

\title{
Combining Spectroscopic and Potentiometric Approaches to Characterize Competitive Binding to Humic Substances
}

Laura Marang, Pascal E. Reiller, Sascha Eidner, Michael Kumke, Marc F. Benedetti

\section{To cite this version:}

Laura Marang, Pascal E. Reiller, Sascha Eidner, Michael Kumke, Marc F. Benedetti. Combining Spectroscopic and Potentiometric Approaches to Characterize Competitive Binding to Humic Substances. Environmental Science and Technology, 2008, 42 (14), pp.5094-5098. 10.1021/es702858p . cea-00311465

\section{HAL Id: cea-00311465 \\ https://hal-cea.archives-ouvertes.fr/cea-00311465}

Submitted on 18 Aug 2008

HAL is a multi-disciplinary open access archive for the deposit and dissemination of scientific research documents, whether they are published or not. The documents may come from teaching and research institutions in France or abroad, or from public or private research centers.
L'archive ouverte pluridisciplinaire HAL, est destinée au dépôt et à la diffusion de documents scientifiques de niveau recherche, publiés ou non, émanant des établissements d'enseignement et de recherche français ou étrangers, des laboratoires publics ou privés.

\section{(ㅇ)(1) $\$$}

Distributed under a Creative Commons Attribution - NonCommercial - NoDerivatives| 4.0 


\section{Combining Spectroscopic and Potentiometric}

\section{Approach to Characterize Competitive Binding to}

\section{Humic Substances.}

LAURA MARANG,${ }^{a, b, \dagger}$ PASCAL E. REILLER, ${ }^{a}$ SASCHA EIDNER, ${ }^{c}$ MICHAEL U. KUMKE, ${ }^{c}$ MARC F. BENEDETTI ${ }^{b, *}$

CEA Saclay, Nuclear Energy Division, DPC/SECR, Laboratoire de Spéciation des Radionucléides et des Molécules, Bâtiment 391 - P.C. 33, BP 11, F-91191 Gif sur Yvette, France, Laboratoire de Géochimie des Eaux, Université Paris Diderot, IPGP and UMR CNRS 71574, Case Postale 7052, 75251 Paris Cedex 05, France, Institute of Chemistry, University of Potsdam, Karl-LiebknechtStraße 24-25, 14476 Potsdam-Golm, Germany

\footnotetext{
*Corresponding author fax: +33 1442760 38; e-mail, benedetti@ipgp.jussieu.fr

a Laboratoire de Spéciation des Radionucléides et des Molécules

${ }^{\mathrm{b}}$ University of Potsdam

${ }^{\mathrm{c}}$ Université Paris Diderot

${ }^{\dagger}$ Present address: Groupe Evaluation des Risques Environnementaux et Sanitaires, EDF R\&D, Département LNHE, 6 Quai Watier, F-78401 Chatou, France.
} 


\section{ABSTRACT}

In an area that contains high concentrations of natural organic matter, it is expected that it plays an important role on the behavior of rare earth elements (REE), like europium, and of trivalent actinides. Competitive interactions with $\mathrm{H}^{+}$, inorganic species, major cations, e.g., $\mathrm{Ca}$ (II) or $\mathrm{Mg}$ (II), could influence these metals transport and bioavailability. Competitive experiments between cations, which can bind differently to humic substances and $\mathrm{Eu}^{3+}$, will bring an improved understanding of the competitive mechanisms. The aim of this study is to acquire data for $\mathrm{Eu}(\mathrm{III}) / \mathrm{Cu}(\mathrm{II})$ and $\mathrm{Eu}(\mathrm{III}) / \mathrm{Ca}(\mathrm{II})$ competitive binding to a sedimentary originated humic acid (Gorleben, Germany). The NICA-Donnan parameters for $\mathrm{Ca}^{2+}, \mathrm{Cu}^{2+}$, and $\mathrm{Eu}^{3+}$ obtained from competitive binding experiments using $\mathrm{Ca}^{2+}$ or $\mathrm{Cu}^{2+}$ ion selective electrodes were used to model time-resolved laser fluorescence spectroscopy (TRLFS) measurements. $\mathrm{Eu}^{3+}$ and $\mathrm{Cu}^{2+}$ are in direct competition for the same type of sites, whereas $\mathrm{Ca}^{2+}$ has an indirect influence through electrostatic binding.

KEYWORDS humic acid, competition, rare earth elements, lanthanides, TRLFS

BRIEFS: Competitive binding between a rare earth analogue and divalent cations onto humic substances reveals different binding sites for the rare earth elements.. 


\section{Introduction}

Natural organic matter (NOM) plays a major role on the geochemical cycle and transport of major and trace elements in natural and contaminated environment. The knowledge of radionuclides transport in the geosphere is a key issue for the assessment of the safety of nuclear facilities. Humic acids (HA) and fulvic acids (FA) provide excellent analogues for the reactive components of NOM in soils and rivers and can be used to model metal ion binding to NOM. Several f-block elements, which have a water stable +III redox state, are long-lived radionuclides (RN) typically the actinides (An) like $\mathrm{Pu}, \mathrm{Am}$ and $\mathrm{Cm}$, and among the lanthanide (Ln) the ${ }^{151} \mathrm{Sm}$ isotope. Moreover, analogies between $\mathrm{An}^{3+}$ and $\mathrm{Ln}^{3+}$ ions are sometimes used to implement database. Complexation of Eu(III) with HA or FA can be considered as an analog to actinide complexation to NOM as well as a relevant test element for a better understanding of rare earth elements (REE) behavior in complex geochemical environment, i.e., soil solution, soils, and aquifers.

Competitive interactions with $\mathrm{H}^{+}$, inorganic species, and major cations $\left(\mathrm{Ca}^{2+}, \mathrm{Mg}^{2+} \ldots\right)$ could influence REE transport and bioavailability. Hence, it is important to obtain reliable $\mathrm{Eu}^{3+}$ binding data for organic and inorganic ligands and to calibrate models in order to predict $\mathrm{Eu}^{3+}$ speciation in natural multicomponent systems (i.e., soils and rivers). Data sets for $\mathrm{Eu}^{3+}$ binding to HA and FA are available for different salinities and $\mathrm{pH}$ values (1-4). However, these data sets are frequently not interpreted within consistent modeling framework approaches. Moreover, studies integrating competitive binding effects are scarce. These competition mechanisms between classes of cations (5-7), whereas others are not (8-11), can be interpreted in the framework of NICA-Donnan model (12-14). Competitive experiments between $\mathrm{Eu}^{3+}$ and cations that can bind differently to humic substances could complement the available information. (12)

Since the work from Milne et al. $(13,14)$, NICA-Donnan generic data for HA and FA proton and metal binding are available. It has been shown that these data can be used, in a first approximation to describe the complexation comportment of various humic samples $(15,16)$, even if specific data are often still needed in order to increase the confidence in both the model prediction and of the 
generic data $(17,18)$. The aim of this work is to obtain laboratory data that can be use to implement models which can help in understanding environmental situation. This is done under experimental conditions limiting the formation of other $\mathrm{Eu}(\mathrm{III})$ complexes (e.g., $\mathrm{Eu}(\mathrm{OH})_{n}{ }^{3-n}$ and $\left.\mathrm{Eu}\left(\mathrm{CO}_{3}\right)_{m}{ }^{3-2 m}\right)$ in order to facilitate the implementation of the binding parameters in the models. We present data for $\mathrm{Eu}^{3+} / \mathrm{Cu}^{2+}$ and $\mathrm{Eu}^{3+} / \mathrm{Ca}^{2+}$ competitive binding to the Gorleben humic acid (Gohy-573 HA). $\mathrm{Ca}^{2+}$ and $\mathrm{Cu}^{2+}$ were chosen because they are known to bind differently to HS (14), i.e., nonspecific versus specific binding for $\mathrm{Ca}^{2+}$ and $\mathrm{Cu}^{2+}$, respectively. The competitive binding experiments using $\mathrm{Ca}^{2+}$ or $\mathrm{Cu}^{2+}$ ion selective electrodes (ISE) are used to derive the $\mathrm{Ca}^{2+}, \mathrm{Cu}^{2+}$, and $\mathrm{Eu}^{3+}$ parameters for the Gohy-573 HA, extracted from the German repository test site (19), within the NICA-Donnan approach. Then, these parameters are used to model Time Resolved Laser Fluorescence Spectroscopy (TRLFS) measurements. Based on these results the competitive effect of $\mathrm{Ca}^{2+}$ and $\mathrm{Cu}^{2+}$ on $\mathrm{Eu}^{3+}$ speciation is predicted.

\section{Materials and Methods}

Humic Acid Sample. The Gohy-573 HA was extracted from one of the deep groundwaters in the Gorleben area and was provided by Manfred Wolf (Institut für Grundwasserökologie, GSF Forschungszentrum für Umwelt und Gesundheit, Munich, Germany). Its isolation, purification and characterisation are described in detail elsewhere $(19,20)$.

Reagents. The reagents used were $\mathrm{Cu}\left(\mathrm{NO}_{3}\right)_{2}$ (Certiprep, Spex), $\mathrm{Eu}\left(\mathrm{NO}_{3}\right)_{2}$ (europium ICP standard solution, Aldrich), $\mathrm{KNO}_{3}$ (Panreac), $\mathrm{KCl}$ (Suprapur, Merck) for ISE experiments. In the TRLFS experiments the reagents used were $\mathrm{Cu}\left(\mathrm{NO}_{3}\right)_{2}, \mathrm{Ca}\left(\mathrm{NO}_{3}\right)_{2}$ (Certiprep, Spex), $\mathrm{EuCl}_{3}$ (Aldrich) and deionized water (Milli Q, Millipore).

Ion Selective Electrode Measurements. The $\mathrm{pH}$ was measured using a $\mathrm{pH}$ electrode (Metrohm, 6.0133.100) and an Ag/AgCl glass reference electrode (Metrohm, 6.0733.100). After addition of acid or base, the rate of drift for both electrodes was measured after $1 \mathrm{~min}$ and readings were accepted when the drift was less than $0.25 \mathrm{mV} \min ^{-1}$. For each data point, the maximum drift monitoring time was $20 \mathrm{~min}$. The $\mathrm{pH}$ electrode was calibrated with standard buffers (SCHOTT) of 
different $\mathrm{pH}$ (4.01, 6.87, and 9.18, respectively). During the fixed $\mathrm{pH}$ experiment, the $\mathrm{pH}$ was controlled with $\mathrm{CO}_{2}$ free $\mathrm{KOH}(0.01 \mathrm{M})$ and $\mathrm{HNO}_{3}(0.01 \mathrm{M})$.

\section{$\mathrm{Cu}^{2+}$ and $\mathrm{Ca}^{2+}$ Binding to Gohy-573 $\mathrm{HA}$ in the Absence and Presence of $\mathrm{Eu}^{3+}$ at $\mathrm{pH}$ 5.5.}

Performing a speciation calculation without $\mathrm{HA}$, only $\mathrm{Eu}^{3+}, \mathrm{Ca}^{2+}$, and $\mathrm{Cu}^{2+}$ ions are the dominant species in solution under our conditions $(21,22)$. The free $\mathrm{Cu}^{2+}$ and $\mathrm{Ca}^{2+}$ concentrations in solution were measured potentiometrically using a $\mathrm{Cu}^{2+}$ ISE (Metrohm, 6.0508.140), and a $\mathrm{Ca}^{2+}$ ISE (Metrohm, 6.0508.110), respectively. Routine calibrations were performed at $\mathrm{pH} 5.5$ in the absence of $\mathrm{HA}$, in the ranges $0.5 \mu \mathrm{M} \leq[\mathrm{Cu}(\mathrm{II})]_{\text {total }} \leq 1 \mathrm{mM}$ in $1 \mathrm{mM} \mathrm{KNO}_{3}$ background electrolyte, and 0.5 $\mu \mathrm{M} \leq[\mathrm{Ca}(\mathrm{II})]_{\text {total }} \leq 1 \mathrm{mM}$ in $1 \mathrm{mM} \mathrm{KCl}$ background electrolyte.

First, the $\mathrm{Cu}^{2+}$ and $\mathrm{Ca}^{2+}$ parameters were obtained with direct titrations of Gohy-573. Solutions of Gohy-573 HA (60 mg/L for $\mathrm{Cu}^{2+}$, and $200 \mathrm{mg} / \mathrm{L}$ for $\mathrm{Ca}^{2+}$ ) was titrated to $\mathrm{pH}$ 5.5, and then $\mathrm{pH}$ was kept constant for 30 min to stabilize the Gohy-573 HA before titration with (i) $\mathrm{Cu}^{2+}$ in the concentration range of $10-75 \mu \mathrm{M}$, and (ii) $\mathrm{Ca}^{2+}$ in the concentration range of 9-200 $\mu \mathrm{M}$.

Second, the $\mathrm{Eu}^{3+}$ parameters were obtained through competitive experiments with $\mathrm{Cu}^{2+}$ and $\mathrm{Ca}^{2+}$. Solutions of Gohy-573 HA (60 mg/L) containing $20 \mu \mathrm{M}$ of $\mathrm{Cu}^{2+}$, and Gohy-573 HA (200 mg/L) containing $30 \mu \mathrm{M}$ of $\mathrm{Ca}^{2+}$, was titrated to $\mathrm{pH} 5.5$ and then $\mathrm{pH}$ was kept constant for 30 min before titration with $\mathrm{Eu}^{3+}$ in the concentration range of 3-60 $\mu \mathrm{M}$ in the case of $\mathrm{Cu}^{2+}$, and 1-50 $\mu \mathrm{M}$ in the case of $\mathrm{Ca}^{2+}$.

At each step, the concentration of free $\mathrm{M}^{2+}$ was measured after the $\mathrm{pH}$ has been stabilized at $\mathrm{pH}$ 5.5 for $10 \mathrm{~min}$ and the drift of the electrode was less than $0.1 \mathrm{mV} / \mathrm{min}$. The concentration of free $\mathrm{Cu}^{2+}$ in the solution was then corrected from the dilution factor (less than $10 \%$ ), and the amount of $\mathrm{Cu}^{2+}$ bound to Gohy-573 HA was calculated as the difference $\mathrm{M}(\mathrm{II})_{\text {total }}-\mathrm{M}^{2+}$ free.

Time-Resolved Laser Fluorescence measurement. The free europium concentration in solution was measured using TRLFS. All luminescence measurements were performed at ambient temperature. In the TRLFS experiments a wavelength tuneable Nd:YAG/OPO system (Spectra Physics/GWU) operating at $20 \mathrm{~Hz}$ was used as excitation light source. The spectra were recorded 
with an intensified CCD camera (Andor Technology) coupled to a spectrograph (MS257, Oriel Instruments) as detector. For the time-resolved detection the luminescence signal is collected over a certain time interval (gate width) a certain time (gate delay) after excitation by the laser flash. In the experiments the gate delay was set to $10 \mu \mathrm{s}$ and the gate width to $100 \mu \mathrm{s}$. To increase the signal-tonoise ratio, every spectrum for a certain time step results from an accumulation of 10000 single spectra. Europium (III) is often excited at $\lambda_{\text {ex }}=394 \mathrm{~nm}$ which corresponds to its highest resonant absorption transition. We decided to excite the samples at $\lambda_{\mathrm{ex}}=356 \mathrm{~nm}$ and $\lambda_{\mathrm{ex}}=361.7 \mathrm{~nm}$. At $\lambda_{\mathrm{ex}}$ $=361.7 \mathrm{~nm}$ the luminescence spectra contains significant contributions from both free and bound $\mathrm{Eu}^{3+}$ due to efficient indirect excitation via sensitization by the ligand (antenna effect). The luminescence observed corresponds to the ${ }^{5} \mathrm{D}_{0} \rightarrow{ }^{7} \mathrm{~F}_{2}$ hypersensitive transition and the ${ }^{5} \mathrm{D}_{0} \rightarrow{ }^{7} \mathrm{~F}_{1}$ transition of $\mathrm{Eu}^{3+}$. At $\lambda_{\mathrm{ex}}=356 \mathrm{~nm}$, the signal of free $\mathrm{Eu}^{3+}$ in water is negligible under our experimental conditions, and the spectra correspond to $\mathrm{Eu}^{3+}$ bound to Gohy-573 HA. The luminescence spectra were analyzed according to a factor analysis assuming two species. The input parameter were (i) the spectra of a given $\mathrm{Eu}^{3+}$ concentration totally bound to the Gohy-573 HA obtained at $\lambda_{\mathrm{ex}}=356 \mathrm{~nm}$ and (ii) the spectra of free $\mathrm{Eu}^{3+}$ in water for the same total $\mathrm{Eu}^{3+}$ concentration. Before the fit, all spectra obtained in the presence of Gohy-573 HA in solution were corrected from the absorption of Gohy-573 HA. The percentage of free $\mathrm{Eu}^{3+}$ solution could be obtained from this fit with an error of $10 \%$.

\section{$\mathrm{Eu}^{3+}$ Binding to Gohy-573 $\mathrm{HA}$ in the Presence of $\mathrm{Cu}^{2+}$ and $\mathrm{Ca}^{2+}$ at $\mathrm{pH}$ 5.5. Competition} experiments between $\mathrm{Eu}^{3+}$ and $\mathrm{Cu}^{2+}$ were made at a Gohy-573 HA concentration of $20 \mathrm{mg} / \mathrm{L}$ and a total $\mathrm{Eu}^{3+}$ concentration of $7 \mu \mathrm{M}$. The background electrolyte concentration was equal to $1 \mathrm{mM}$ of $\mathrm{KNO}_{3}$ and the $\mathrm{pH}$ was set to $5.5 \pm 0.1$. The total $\mathrm{Cu}^{2+}$ concentration ranged from $1 \mu \mathrm{M}$ to $0.3 \mathrm{mM}$.

Competition between $\mathrm{Eu}^{3+}$ and $\mathrm{Ca}^{2+}$ were made with a Gohy-573 HA concentration of $15 \mathrm{mg} / \mathrm{L}$ and a $\mathrm{Eu}^{3+}$ concentration of $5 \mu \mathrm{M}$; $\mathrm{pH}$ was set at $5.5 \pm 0.1$. The total $\mathrm{Ca}^{2+}$ concentration ranged from $1 \mu \mathrm{M}$ to $0.1 \mathrm{M}$. For total $\mathrm{Ca}^{2+}$ concentrations lower than $0.3 \mathrm{mM}$ the background electrolyte was 
fixed with $1 \mathrm{mM} \mathrm{KNO}_{3}$. For total $\mathrm{Ca}^{2+}$ concentrations ranging from 0.3 to $20 \mathrm{mM}$, it was fixed with $0.1 \mathrm{M} \mathrm{KNO}_{3}$. For total $\mathrm{Ca}^{2+}$ concentrations higher than $20 \mathrm{mM}$ the ionic strength was fixed by the $\mathrm{Ca}^{2+}$ salt added in the system and calculated for each data points.

Modeling. Chemical calculations were made using ECOSAT (23), which includes speciation with inorganic ligands and the NICA-Donnan model, abundantly described elsewhere (12), which describes complexation of metals and protons with humic substances. Deviation from nonideality for inorganic species is accounted with the Davies equation.

\section{Results and Discussion}

ISE Data: $\mathrm{Ca}^{2+}$ and $\mathrm{Cu}^{2+}$ Binding to Gohy-573 HA in the Presence and Absence of Eu${ }^{3+}$. The $\mathrm{Cu}^{2+}$ and $\mathrm{Ca}^{2+}$ potentiometric titrations are shown in Figure 1. The amounts of $\mathrm{Cu}^{2+}$ and $\mathrm{Ca}^{2+}$ bound are, in both cases, in the range of previously published data for humic acids of different origin (12, 14). However, the steeper slope of the $\mathrm{Ca}^{2+}$ binding isotherm, compared to the one obtained in a previous study (24), indicates that the Gohy-573 HA is more chemically heterogeneous than the purified peat humic acid, because the degree of heterogeneity controls the slope of the binding isotherm (12).

The effect of $\mathrm{Eu}^{3+}$ is more significant on $\mathrm{Cu}^{2+}$ than on $\mathrm{Ca}^{2+}$ binding (Figure 2). Indeed, for $\mathrm{Eu}^{3+}$ added to the $\mathrm{Cu}^{2+}$ solution with final $\mathrm{Eu}^{3+}$ concentrations ranging from 0 to $60 \mu \mathrm{M}$, the percentage of free $\mathrm{Cu}^{2+}$ measured in solution increases from 0 to $25 \%$ of the total $\mathrm{Cu}^{2+}$ amount corresponding to an increase of the free $\mathrm{Cu}^{2+}$ in solution by a factor of 10 . Whereas in the experiments with $\mathrm{Ca}^{2+}$, for an $\mathrm{Eu}^{3+}$ concentration ranging from 0 to $60 \mu \mathrm{M}$, the percentage of free $\mathrm{Ca}^{2+}$ measured in solution varies only by a few percent: the $\left[\mathrm{Ca}^{2+}\right]_{\text {free }}$ in solution is increased by a factor of 1.5 . Experiments with higher $\mathrm{Eu}^{3+}$ concentrations were not performed because they would be irrelevant for most natural or repository conditions.

TRLFS data: $\mathrm{Eu}^{3+}$ Binding to Gohy-573 $\mathrm{HA}$ in the Presence of $\mathrm{Ca}^{2+}$ and $\mathrm{Cu}^{2+}$. The effect of $\mathrm{Cu}^{2+}$ on $\mathrm{Eu}^{3+}$ binding to Gohy-573 HA measured by TRLFS is more significant than the effect of 
$\mathrm{Ca}^{2+}$ (Figure 3). The addition of $\mathrm{Cu}^{2+}$ concentrations ranging from 0 to $0.4 \mathrm{mM}$ increases $\left[\mathrm{Eu}^{3+}\right]_{\text {free }}$ measured in solution by a factor of 6 . Whereas, in order to have the same effect with $\mathrm{Ca}^{2+}$ on the $\mathrm{Eu}^{3+}$ binding, it is necessary to raise the $\mathrm{Ca}^{2+}$ concentration up to $0.1 \mathrm{M}$. The competitive $\mathrm{Ca}^{2+}$ experiments done with an ionic strength fixed to $1 \mathrm{mM}$, corresponding to low calcium concentrations, have no effect on $\mathrm{Eu}^{3+}$ binding to Gohy-573 HA. From these competitive experiments, we can conclude that competition between $\mathrm{Cu}^{2+}$ and $\mathrm{Eu}^{3+}$ is more important than for $\mathrm{Ca}^{2+}$ even at high concentrations. These differences are accounted for if $\mathrm{Cu}^{2+}$ and $\mathrm{Eu}^{3+}$ compete for the same binding sites within a given range of total $\mathrm{Cu}^{2+}$ and $\mathrm{Eu}^{3+}$ concentrations. The $\mathrm{Ca}^{2+}$ data show that nonspecific binding is negligible in the case of $\mathrm{Eu}^{3+}$ even at low ionic strength.

Modeling: Specific NICA-Donnan Gohy-573 HA Parameters for $\mathrm{Eu}^{3+}, \mathrm{Cu}^{2+}$ and $\mathrm{Ca}^{2+}$ Derived from ISE Experiments. Using the generic parameter values for $\mathrm{Eu}^{3+}, \mathrm{Cu}^{2+}$, and $\mathrm{Ca}^{2+}$ parameters (14), a reasonable description of the competitive effect of $\mathrm{Eu}^{3+}$ on $\mathrm{Ca}^{2+}$ and $\mathrm{Cu}^{2+}$ binding to Gohy-573 HA could be achieved (data not shown). However, to have an accurate description of the actual competitive processes, we have determined (Table 1) the specific Gohy-573 HA NICADonnan parameters for $\mathrm{Ca}^{2+}, \mathrm{Cu}^{2+}$, and $\mathrm{Eu}^{3+}$, and proton parameters were taken form ref (17). The best-fitted ISE data result in an increase in $\log \tilde{\mathrm{K}}_{\mathrm{i}, \mathrm{Cu}^{2+}}$ for both types of sites and to decrease log $\tilde{\mathrm{K}}_{1, \mathrm{Eu}^{3+}}$ for the carboxylic type of sites compared to the generic values in (14). The $\mathrm{Ca}^{2+}$ ISE experiments could be described without changing the generic parameter values, since binding occurred mostly in the Donnan phase (non-specific binding) for this low ionic strength.

The specific parameters can be used to simulate the speciation of each cation in the Gohy-573 HA (Figure 5) for the experimental conditions applied in the TRLFS measurements. The calculations were done for two ionic strengths in case of $\mathrm{Eu}^{3+}(1 \mathrm{mM}$ and $0.1 \mathrm{M})$, for one ionic strength in case of $\mathrm{Cu}^{2+}(1 \mathrm{mM})$, and to $0.1 \mathrm{M}$ for $\mathrm{Ca}^{2+}$. For $\mathrm{Cu}^{2+}$ and $\mathrm{Eu}^{3+}$, binding occurs mostly at the carboxylic type of sites. Thomason et al. have investigated the binding of $\mathrm{Eu}^{3+}$ to aquatic humic substances using lanthanide ion probe spectroscopy (25). The results, which refer to $\mathrm{pH} 3.5$, showed that at the lowest europium loadings approximately four humic ligands atoms where involved in metal binding. 
At higher loadings, fewer ligand atoms were involved. The authors consider a series of mono-, bi-, tri-, and tetra-dendate binding sites, probably due to carboxylate groups. In the NICA-Donnan model, the ratio between the non ideality parameter for metal and proton $\left(n_{\mathrm{M}} / n_{\mathrm{H}}\right)$ per type of sites is equivalent to the experimental value of the proton-metal exchange ratio (12), i.e., the number of protons expelled for each metal bound to HA. The values of $n_{1, \mathrm{Eu}} / n_{1, \mathrm{H}}=0.75$ and $n_{2, \mathrm{Eu}} / n_{2, \mathrm{H}}=0.55$ suggest that $\mathrm{Eu}^{3+}$ binds most likely in bidentate form. This conclusion is supported by the study of Shin et al. (26) where two contributions were fitted after excitation in the ${ }^{5} \mathrm{D}_{0} \rightarrow{ }^{7} \mathrm{~F}_{0}$ band suggesting that humic and fulvic acids have two different chemical environments for the binding of $\mathrm{Eu}^{3+}$. These two environments were proposed as phthalate like sites but could also be salicylate. Cabaniss (27) measured synchronous fluorescence spectra of humic extracts and noted that the quenching of the intrinsic fluorescence by $\mathrm{Co}^{2+}, \mathrm{Cu}^{2+}$, and $\mathrm{Pb}^{2+}$ were similar at $\mathrm{pH} 5$ and 7.5 suggesting that these metal ions may bind to the same type of sites.

The fitting of the $\mathrm{Ca}^{2+}$ data (Figure 1) is poor. It is important to give a reasonable description of the binding due to the nonspecific interaction and because the Donnan model was proved to be relevant to account for ionic strength effect for HA (28). The most likely reason is a poor knowledge of the actual ionic strength as at very low background electrolyte concentration a small underestimation strongly influences the model outputs. The $\mathrm{pH}$ was fixed by adding small amount of $\mathrm{KOH}$ and $\mathrm{HNO}_{3}$; this increases the ionic strength of the solution (calculation not shown here). The ionic strength being higher than expected, i.e., $1.5 \mathrm{mM}$, a more accurate description of the $\mathrm{Ca}^{2+}$ binding is obtained (Figure 1).

Predicting $\mathrm{Ca}^{2+} / \mathbf{E u}^{3+}$ and $\mathrm{Cu}^{2+} / \mathbf{E u}^{3+}$ TRLFS Data. One of the purposes of modeling is the prediction of metal ion speciation in solution in the presence of competing cations. The direct measurements of all free metal ion concentrations can be difficult and time-consuming. Consequently, it is important to check the ability of the NICA-Donnan model to predict the metal ion speciation in a competitive environment. The free $\mathrm{Eu}^{3+}$ concentrations were determined in TRLFS experiments as a function of the total $\mathrm{Ca}^{2+}$ or $\mathrm{Cu}^{2+}$ concentration and were used to validate 
the NICA-Donnan parameters (Figure 3, Table 1). Figure 4 presents the free $\mathrm{Eu}^{3+}$ in solution measured by TRLFS vs the free $\mathrm{Eu}^{3+}$ calculated by the NICA-Donnan model. Both are in good agreement as the data points cluster along the one to one line meaning that the increasing competitive effects with the increase of the total $\mathrm{Cu}^{2+}$ or $\mathrm{Ca}^{2+}$ concentration are accurately predicted. The model however overestimates the free $\mathrm{Eu}^{3+}$ in solution for total $\mathrm{Cu}^{2+}$ concentration higher than $0.08 \mathrm{mM}$ (Figure 3 and Figure 4). This could be induced by the lack of data points at higher $\mathrm{pH}$ values that are needed to adjust $\log \tilde{\mathrm{K}}_{2}$ corresponding to phenolic type of sites site for both cations. Here, generic $\log \widetilde{\mathrm{K}}_{2, \mathrm{Eu}^{3+}}$ for phenolic type of sites were used (14) without any further adjustment, whereas $\log \widetilde{\mathrm{K}}_{2, \mathrm{Cu}^{2+}}$ was adjusted. From the estimation (29), for high $\mathrm{Cu}^{2+}$ concentration the proportion of phenolic type of sites should be as important as for the carboxylic ones under our conditions. An underestimation of the $\log \tilde{\mathrm{K}}_{2, \mathrm{Cu}^{2+}}$ could result, because of a stronger $\mathrm{Cu}^{2+}$ competitive binding, in an increased calculated concentration of free $\mathrm{Eu}^{3+}$ in solution. Further works in order to obtain data obtained at higher $\mathrm{pH}$ under different metal to ligand ratio and $\mathrm{Cu}^{2+}$ concentrations are needed to test this hypothesis.

For $\mathrm{Ca}^{2+}$ competitive experiments, the model describes very well the experimental data even when the ionic strength is controlled by the $\mathrm{Ca}^{2+}$ salt added in the system $(0.1 \mathrm{M}<I<0.3 \mathrm{M})$ (Figure 3 and Figure 4), mainly because the interaction of $\mathrm{Ca}^{2+}$ occurs through electrostatic effects. The agreement between experimental and calculated speciation therefore validates the NICA-Donnan parameters used for the simulation of competitive binding.

Implications on the Mobility of REE and Actinides (III). $\mathrm{Eu}^{3+}$, which could be considered as analog for other $\mathrm{Ln}^{3+}$ and $\mathrm{An}^{3+}$ ions, is strongly bound to Gohy-573 HA. Its mobility maybe determined by the colloidal transport, in particularly by NOM as evidenced in ref (30). $\mathrm{Ln}^{3+} / \mathrm{An}^{3+}$ NOM colloids should be less affected in terms of $\mathrm{Ln}^{3+} / \mathrm{An}^{3+}$ release in case of a transport through a $\mathrm{Ca}^{2+}$-rich aquifer (calcareous soil or solution, saline solution) since no desorption is expected because of the lack of competition between $\left(\mathrm{Ln}^{3+} / \mathrm{An}\right)^{3+}$ and $\mathrm{Ca}^{2+}$. Nevertheless, variation of colloid 
stability and particularly of humic colloid size $(31,32)$ with $\mathrm{Ca}^{2+}$ and $\mathrm{Mg}^{2+}$ concentration would then be a limiting factor of humic colloid-borne migration of europium. Nevertheless, $\mathrm{Ln}^{3+} / \mathrm{An}^{3+}$ fate can be affected in presence of trace elements with high affinity for carboxylic type of sites, e.g., $\mathrm{Pb}^{2+}$ and $\mathrm{Zn}^{2+}$, and also by $\mathrm{Cu}^{2+}$ under low $\mathrm{pH}$ conditions (14). In such cases significant amounts of $\mathrm{Ln}^{3+} / \mathrm{An}^{3+}$ can be released in solution as free metal and be more available for biouptake. An even stronger effect can be expected in case $\mathrm{Al}^{3+}$ or $\mathrm{Fe}^{3+}$ are present in solution since the trivalent cations would compete for the same sites $(11,16)$. Further work is needed in order to refine the analysis at higher pHs where the phenolic type of sites should be more influent and where side reactions leading to the formation of either $\mathrm{Eu}(\mathrm{OH})_{n}{ }^{3-n}$ or $\mathrm{Eu}\left(\mathrm{CO}_{3}\right)_{n}{ }^{3-2 n}$ will take place.

\section{Acknowledgments}

This work was financed through "FUNMIG project" (EC: FUNMIG- NUWASTE-2004-3.2.1.11), and the MRTRA project of the Risk Control Domain of CEA (CEA/DEN/DDIN). We thank Badia Amekraz, Francis Claret, Christophe Moulin (CEA), and Gunnar Buckau (INE) for their strong support and helpful discussions.

\section{References}

(1) Norden, M.; Ephraim, J. H.; Allard, B. The binding of strontium and europium by an aquatic fulvic acid - ion exchange distribution and ultrafiltration studies. Talanta 1993, 40, 1425-1432.

(2) Torres, R. A.; Choppin, G. R. Europium(III) and americium(III) stability constants with humic acid. Radiochim. Acta 1984, 35, 143-148.

(3) Lead, J. R.; Hamilton-Taylor, J.; Peters, A.; Reiner, S.; Tipping, E. Europium binding by fulvic acids. Anal. Chim. Acta 1998, 239, 171-180.

(4) Chung, K. H.; Lee, W.; Cho, Y.; Choi, G. S.; Lee, C. W. Comparison of synchronous and laser-induced fluorescence spectroscopy applied to the Eu(III)-fulvate complexation. Talanta 2005, 65, 389-395.

(5) Kerndorff, H.; Schnitzer, M. Sorption of metals on humic acid. Geochim. Cosmochim. Acta 1980, 44, 1701-1708.

(6) Alberts, J. J.; Filip, Z. Metal binding in estuarine humic and fulvic acids: FTIR analysis of humic acid-metal complexes. Environ. Technol. 1998, 19, 923-931.

(7) Pinheiro, J. P.; Mota, A. M.; Benedetti, M. F. Lead and calcium binding to fulvic acids: Salt effect and competition. Environ. Sci. Technol. 1999, 33, 3398-3404.

(8) Hering, J. G.; Morel, F. M. M. Humic acid complexation of calcium and copper. Environ.

Sci. Technol. 1988, 22, 1234-1237. 
(9) Hering, J. G.; Morel, F. M. M. Kinetics of trace metal complexation: role of alkaline-earth metals. Environ. Sci. Technol. 1988, 22, 1469-1478.

(10) Tipping, E.; Backes, C. A.; Hurley, M. A. The complexation of protons, aluminum and calcium by aquatic humic substances - A model incorporating binding-site heterogeneity and macroionic effects. Water Res. 1988, 22, 597-611.

(11) Pinheiro, J. P.; Mota, A. M.; Benedetti, M. F. Effect of aluminum competition on lead and cadmium binding to humic acids at variable ionic strength. Environ. Sci. Technol. 2000, 34, 5137-5143.

(12) Kinniburgh, D. G.; van Riemsdijk, W. H.; Koopal, L. K.; Borkovec, M.; Benedetti, M. F.; Avena, M. J. Ion binding to natural organic matter: competition, heterogeneity, stoichiometry and thermodynamic consistency. Colloids Surf., A 1999, 151, 147-166.

(13) Milne, C. J.; Kinniburgh, D. G.; Tipping, E. Generic NICA-Donnan model parameters for proton binding by humic substances. Environ. Sci. Technol. 2001, 35, 2049-2059.

(14) Milne, C. J.; Kinniburgh, D. G.; Van Riemsdijk, W. H.; Tipping, E. Generic NICA-Donnan model parameters for metal-ion binding by humic substances. Environ. Sci. Technol. 2003, 37, 958-971.

(15) Benedetti, M. F. Metal ion binding to colloids from database to field systems. J. Geochem. Explor. 2006, 88, 81-85.

(16) Weber, T.; Allard, T.; Tipping, E.; Benedetti, M. F. Modeling iron binding to organic matter. Environ. Sci. Technol. 2006, 40, 7488-7493.

(17) Marang, L.; Reiller, P.; Pepe, M.; Benedetti, M. F. Donnan membrane approach: From equilibrium to dynamic speciation. Environ. Sci. Technol. 2006, 40, 5496-5501.

(18) Marang, L.; Reiller, P.; Jouvin, D.; Benedetti, M. F. U(VI) and Mg(II) binding to humic substances: speciation and competition. Appl. Geochem. submitted.

(19) Wolf, M.; Buckau, G.; Geyer, S. Isolation and characterization of new batches of Gohy-573 humic and fulvic acids. In Humic Substances in Performance Assessment of Nuclear Waste Disposal: Actinide and Iodine Migration in the Far-Field. Second Technical Progress Report; Buckau, G., Ed.: Karlsruhe, 2004; pp 111-124. http://bibliothek.fzk.de/zb/berichte/FZKA6969.pdf (20) Buckau, G.; Artinger, R.; Fritz, P.; Geyer, S.; Kim, J. I. Origin and mobility of humic colloids in the Gorleben aquifer system. Appl. Geochem 2000, 15, 171-179.

(21) Baes, C. F.; Mesmer, R. E. The hydrolysis of cations; Wiley Interscience Publication: NewYork, 1976.

(22) Hummel, W.; Berner, U.; Curti, E.; Pearson, F. J.; Thoenen, T. Nagra/PSI Chemical Thermodynamic Data Base 01/01, NTB 02-06, NAGRA, Parkland, Florida, 2002.

(23) Keizer, M. G.; Van Riemsdijk, W. H. A Computer Program for the Calculation of Chemical Speciation and Transport in Soil-Water Systems (ECOSAT 4.7). Agricultural University of Wageningen: Wageningen, 1994.

(24) Benedetti, M. D. F.; Milne, C. J.; Kinniburgh, D. G.; van Riemsdijk, W. H.; Koopal, L. K. Metal ion binding to humic substances: application of the non-ideal competitive adsorption model. Environ. Sci. Technol. 1995, 29, 446-457.

(25) Thomason, J. W.; Susetyo, W.; Carreira, L. A. Fluorescence studies of metal humic complexes with the use of lanthanide ion probe spectroscopy. Appl. Spectrosc. 1996, 50, 401-408.

(26) Shin, H. S.; Rhee, S. W.; Lee, B. H.; Moon, C. H. Metal binding sites and partial structures of soil fulvic and humic acids compared: Aided by Eu(III) luminescence spectroscopy and

DEPT/QUAT C-13 NMR pulse techniques. Org. Geochem. 1996, 24, 523-529.

(27) Cabaniss, S. E. Synchronous fluorescence-spectra of metal-fulvic acid complexes. Environ.

Sci. Technol. 1992, 26, 1133-1139.

(28) Avena, M. J.; Koopal, L. K.; van Riemsdijk, W. H. Proton binding to humic acids: Electrostatic and intrinsic interaction. J. Colloid Interface Sci. 1999, 217, 37-48.

(29) Kinniburgh, D. G.; Milne, C. J.; Benedetti, M. D. F.; Pinheiro, J. P.; Filius, J.; van Riemsdijk, W. H. Metal ion binding by humic acid: Application of the NICA-Donnan model. Environ. Sci. Technol. 1996, 30, 1687-1698. 
(30) Artinger, R.; Schuessler, W.; Schaefer, T.; Kim, J. I. A kinetic study of Am(III)/humic colloid interactions. Environ. Sci. Technol. 2002, 36, 4358-4363.

(31) Caceci, M.; Moulin, V. Investigations of humic acid samples of different sources by photon correlation spectroscopy. In Lecture Notes in Earth Sciences, Humic Substances in the Aquatic and Terrestrial Environment; Allard, B., Boren, H., Grimwall, A., Eds.; Lecture Notes in Earth Sciences; Springer: Berlin, 1991; Vol. 33, pp 97-104.

(32) Yates, L. M.; von Wandruszka, R. Effects of $\mathrm{pH}$ and metals on the surface tension of aqueous humic materials. Soil Sci. Soc. Amer. J. 1999, 63, 1645-1649. 
Table 1. Parameters Derived Using the NICA-Donnan Model ${ }^{\mathrm{a}}$

\begin{tabular}{lllll}
\hline & $n_{1}$ & $\log \tilde{\mathrm{K}}_{1}$ & $\boldsymbol{n}_{2}$ & $\log \tilde{\mathrm{K}}_{2}$ \\
\hline $\mathrm{H}^{+}$ & 0.8 & 4.11 & 0.65 & 8.92 \\
$\mathrm{Cu}^{2+}$ & 0.6 & 2.85 & 0.34 & 7 \\
$\mathrm{Ca}^{2+}$ & $0.78^{b}$ & $-1.37^{c}$ & $0.75^{c}$ & $-0.43^{c}$ \\
$\mathrm{Eu}^{3+}$ & 0.6 & 1.8 & $0.36^{c}$ & $3.43^{c}$ \\
\hline
\end{tabular}

${ }^{\mathrm{a}}$ The intrinsic heterogeneity parameters $\mathrm{p}$ for Gohy-573 HA are $\mathrm{p}_{1}=0.8$ and $\mathrm{p}_{2}=0.41$ and site density $\mathrm{Q}_{1}=2.63 \mathrm{~mol} \mathrm{~kg}^{-1}$ and $\mathrm{Q}_{2}=3.08 \mathrm{~mol} \mathrm{~kg}^{-1}$ (17), ${ }^{\mathrm{b}}$ Specific parameters for Gohy-573 (17), ${ }^{c}$ Generic parameters (14). 
Figure 1. $\mathrm{Cu}^{2+}$ and $\mathrm{Ca}^{2+}$ binding isotherms to Gohy-573 HA at $\mathrm{pH} 5.5$ with a salt concentration of $I=1 \mathrm{mM} \mathrm{KNO}_{3}$. The $\mathrm{Cu}^{2+}$ and $\mathrm{Ca}^{2+}$ binding isotherms to Gohy-573 HA were measured with $\mathrm{Cu}^{2+}$ and $\mathrm{Ca}^{2+}$ ISE, respectively. $\mathrm{Cu}^{2+}$ binding isotherms correspond to a total amount of $60 \mathrm{mg} / \mathrm{L}$ Gohy-573 HA with a $10 \leq[\mathrm{Cu}]_{\text {Total }}(\mu \mathrm{M}) \leq 75 . \mathrm{Ca}^{2+}$ binding isotherms correspond to a total amount of $200 \mathrm{mg} / \mathrm{L}$ Gohy-573 HA with $9 \leq[\mathrm{Ca}]_{\text {Total }}(\mu \mathrm{M}) \leq 200$. All data points are used to obtain NICADonnan parameters given in Table 1 corresponding to the fitted model line for an ionic strength of 1 or $1.5 \mathrm{mM} \mathrm{KNO}_{3}$.

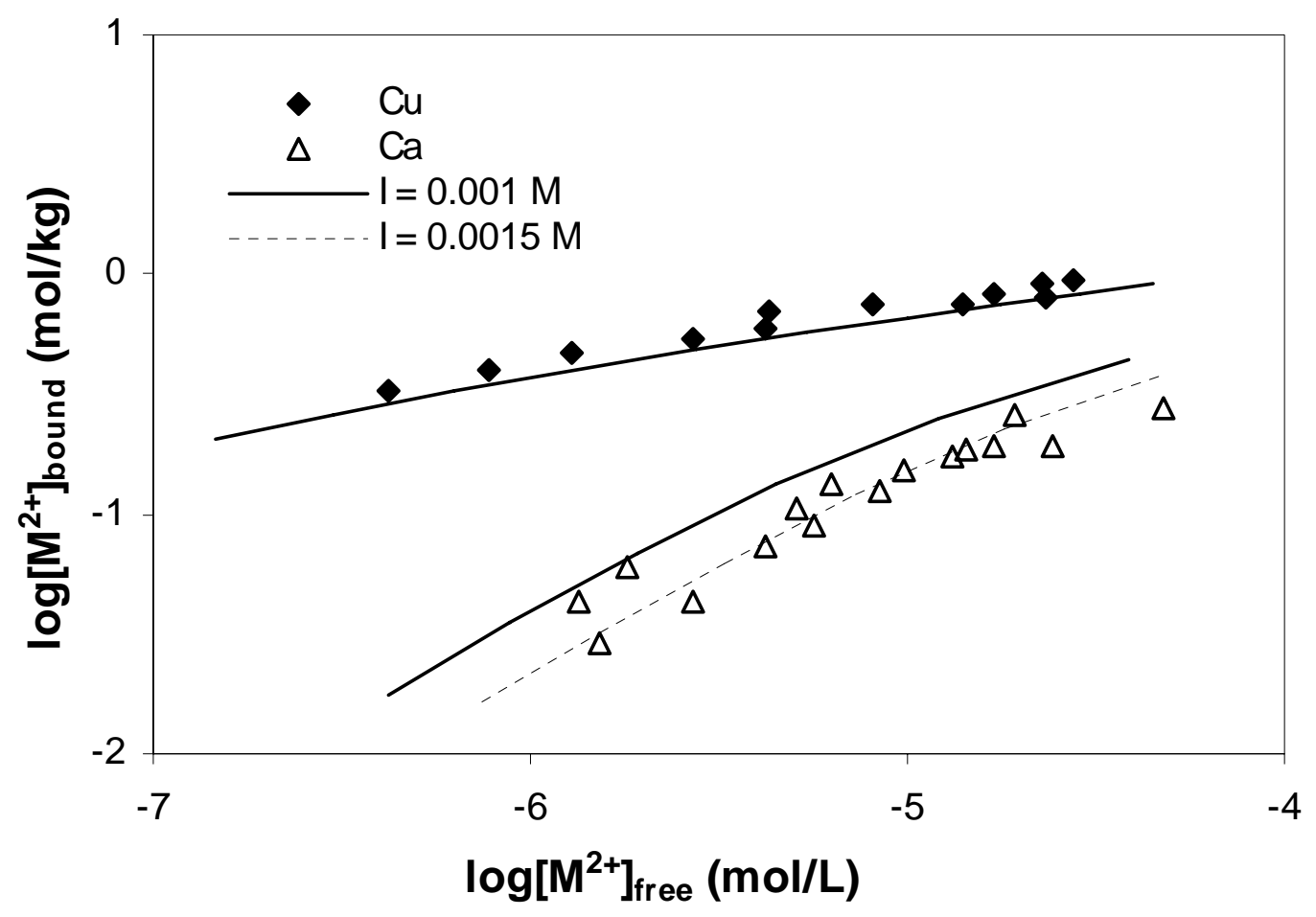


Figure 2. $\mathrm{Eu}^{3+} / \mathrm{Cu}^{2+}$ competitive binding to Gohy-573 HA (a) and $\mathrm{Eu}^{3+} / \mathrm{Ca}^{2+}$ competitive binding to Gohy-573 HA (b) at $\mathrm{pH} 5.5$ with a salt concentration of $I=1 \mathrm{mM} \mathrm{KNO}$. The $\mathrm{Cu}^{2+}$ and $\mathrm{Ca}^{2+}$ binding to Gohy-573 HA were followed with $\mathrm{Cu}^{2+}$ and $\mathrm{Ca}^{2+}$ ISE, respectively. $\mathrm{Eu}^{3+} / \mathrm{Cu}^{2+}$ competitive experiments correspond to a total amount of $60 \mathrm{mg} / \mathrm{L}$ Gohy-573 HA with $[\mathrm{Cu}]_{\text {Total }}=20$ $\mu \mathrm{M}$ and $3 \leq[\mathrm{Eu}]_{\text {Total }}(\mu \mathrm{M}) \leq 60 . \mathrm{Eu}^{3+} / \mathrm{Ca}^{2+}$ competitive experiments correspond to a total amount of $200 \mathrm{mg} / \mathrm{L}$ Gohy-573 HA with a $[\mathrm{Ca}]_{\text {Total }}=30 \mu \mathrm{M}$ and with $1 \leq[\mathrm{Eu}]_{\text {Total }}(\mu \mathrm{M}) \leq 50$. All data points are used to obtain NICA-Donnan parameters given in Table 1 corresponding to the fitted model line.

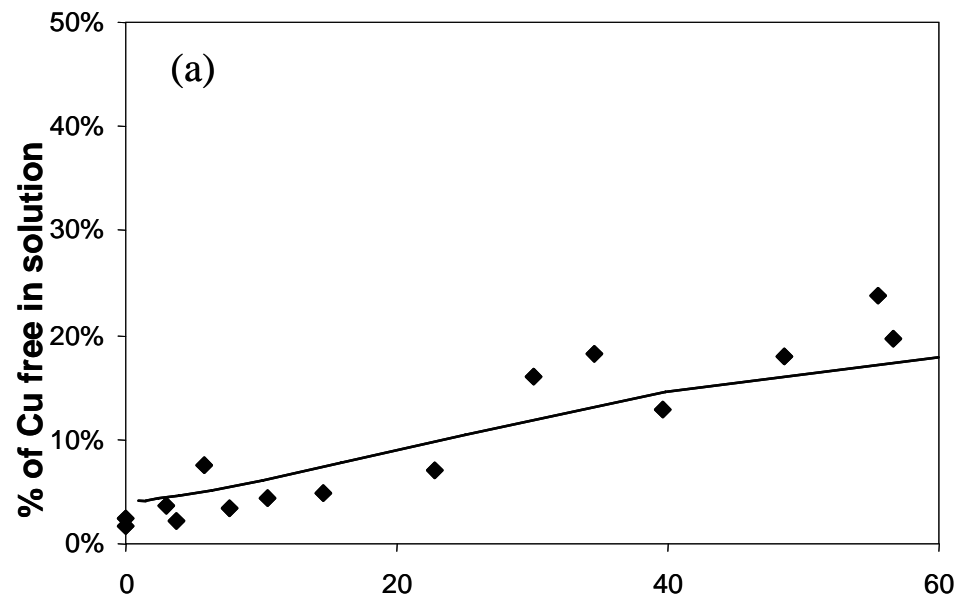

$[\mathrm{Eu}]_{\text {total }}$ in solution $(\mu \mathrm{M})$

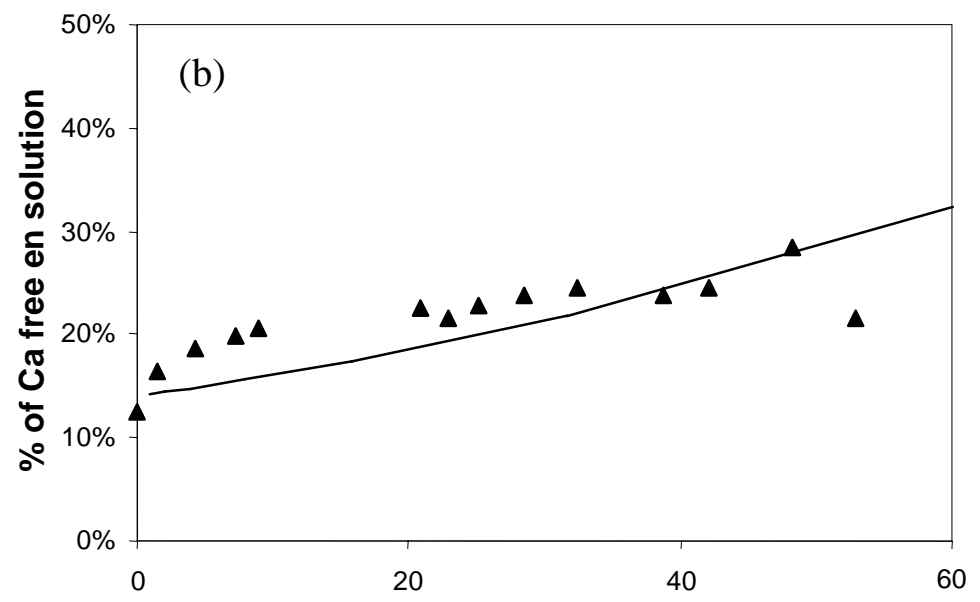

$[E u]_{t o t a l}$ in solution 
Figure 3. $\mathrm{Eu}^{3+} / \mathrm{Cu}^{2+}$ competitive binding to Gohy-573 HA $(20 \mathrm{mg} / \mathrm{L})$ at $\mathrm{pH} 5.5$ with a salt concentration of $I=1 \mathrm{mM}$ and with a $[\mathrm{Eu}]_{\text {Total }}=7 \mu \mathrm{M}$ and $1 \mu \mathrm{M} \leq[\mathrm{Cu}]_{\text {Total }} \leq 0.3 \mathrm{mM}$ (a). $\mathrm{Eu}^{3+} / \mathrm{Ca}^{2+}$ competitive binding to Gohy-573 HA (15 mg/L) at pH 5.5 with an ionic strength of $I=0.1 \mathrm{M}$ and $0.1 \mathrm{M}<I<0.3 \mathrm{M}$ with $[\mathrm{Eu}]_{\text {Total }}=5 \mu \mathrm{M}$ and $1 \mu \mathrm{M} \leq[\mathrm{Ca}]_{\text {Total }} \leq 0.1 \mathrm{M}$ (b). The Eu binding to Gohy-573 HA was measured with TRLFS. The solid and dashed lines represent the NICA-Donnan prediction calculated with parameters of Table 1. Error bars correspond to a $10 \%$ error on TRLFS experiments.

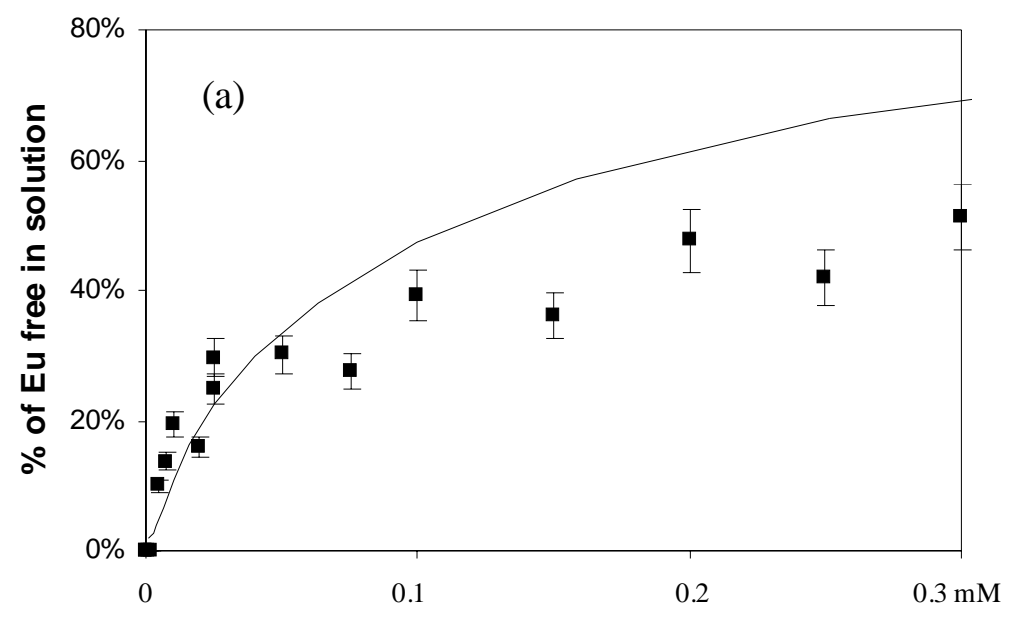

$[\mathrm{Cu}]_{\text {total }}$ in solution (mol/L)

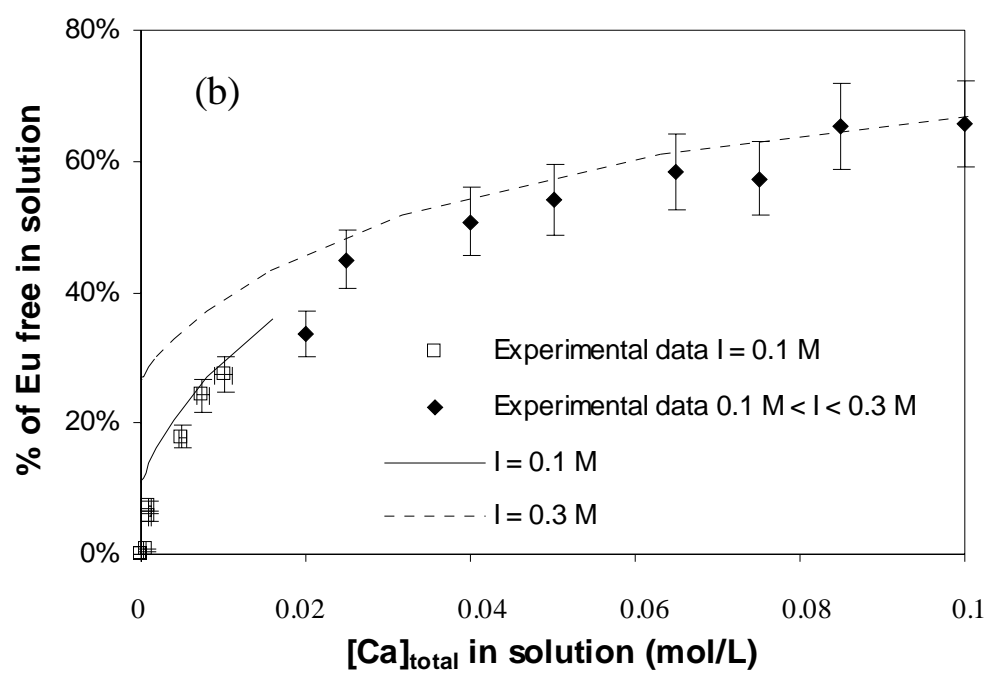


Figure 4. Measured free $\mathrm{Eu}^{3+}$ concentration versus predicted model values for $\mathrm{Eu}^{3+} / \mathrm{Cu}^{2+}$ and $\mathrm{Eu}^{3+} / \mathrm{Ca}^{2+}$ competitive binding experiments on Gohy-573 HA. Error bars correspond to a $10 \%$ uncertainty on TRLFS experiments.

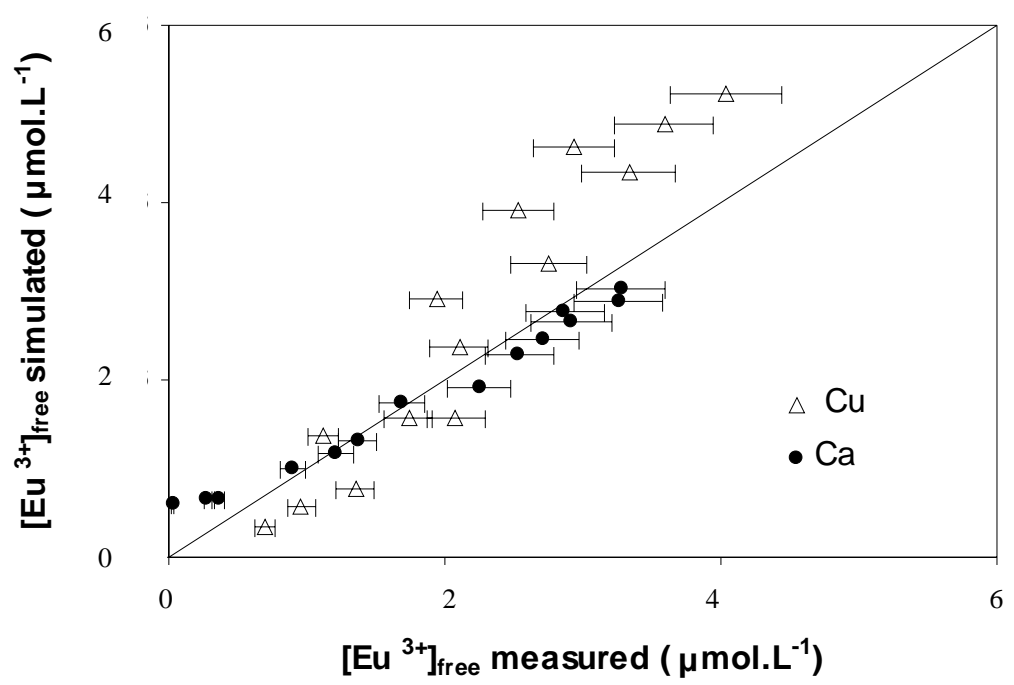


Figure 5. $\mathrm{Eu}^{3+}, \mathrm{Ca}^{2+}$, and $\mathrm{Cu}^{2+}$ individual calculated speciation. The calculations are made with a Gohy-573 HA concentration of $20 \mathrm{mg} / \mathrm{L}$ and a salt concentration of $1 \mathrm{mM}$ for $[\mathrm{Eu}]_{\text {Total }}=7 \mu \mathrm{M}$ (a) and for $[\mathrm{Cu}]_{\text {Total }}=1 \mu \mathrm{M}$ (b). The calculations are made with a Gohy-573 HA concentration of 15 $\mathrm{mg} / \mathrm{L}$ and a salt concentration of $0.1 \mathrm{M}$ for $[\mathrm{Eu}]_{\text {Total }}=5 \mu \mathrm{M}(\mathrm{c})$ and for $[\mathrm{Cu}]_{\text {Total }}=1 \mathrm{mM}(\mathrm{d})$. The specific binding sites $(\square)(\boldsymbol{\square})$ correspond to the carboxylic type of sites and phenolic type of sites, respectively. ( $\square$ ) corresponds to the metal ion located in the humic Donnan phase.

(a) Eu speciation $\mathrm{I}=\mathbf{0} 0.001 \mathrm{M}$

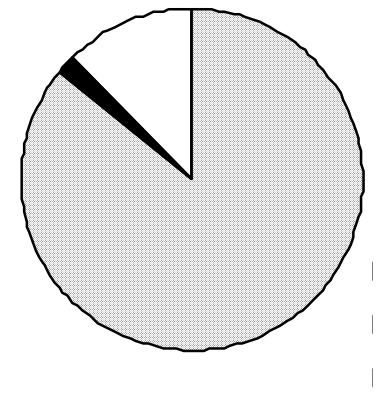

(c) Eu speciation I=0.1 $\mathrm{M}$

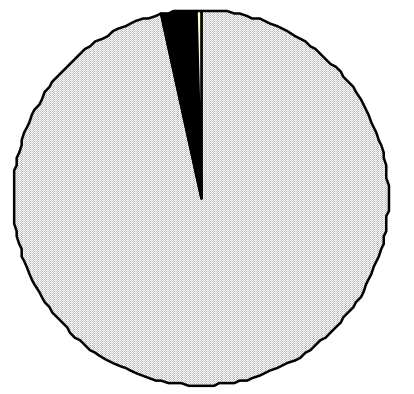

(b) Cu speciation $\mathrm{l}=\mathbf{0 . 0 0 1 \mathrm { M }}$

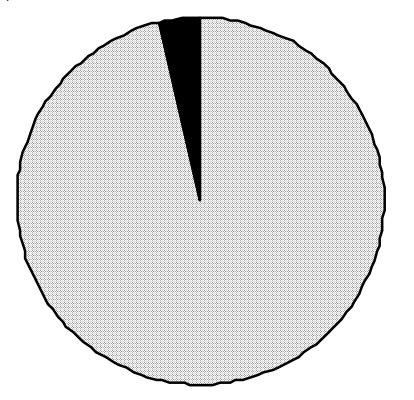

(d) Ca speciation I $=0.1 \mathrm{M}$

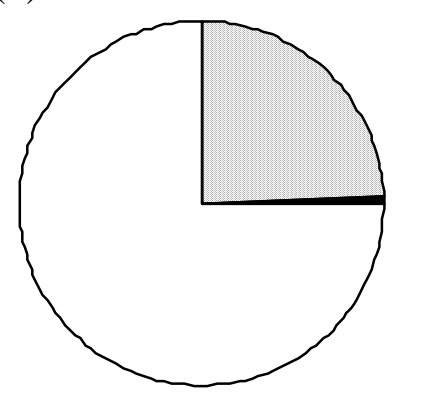

